\title{
Endometrial polyp with chronic endometritis in an African pygmy hedgehog (Atalerix albiventris) - a case report
}

\author{
Maša Efendić ${ }^{1}$, Marko Samardžija², Hrvoje Capak ${ }^{3}$, Goran Bačić², Branka Artuković ${ }^{4}$, \\ Gabrijela Jurkić ${ }^{5}$, Hrvoje Valpotić ${ }^{2}$, Lidija Medven Zagradišnik ${ }^{4}$, Nino Maćešić \\ University of Zagreb, Faculty of Veterinary Medicine, ${ }^{1} \mathrm{PhD}$ student, ${ }^{2} \mathrm{Clinic}$ for Obstetrics and Reproduction, \\ ${ }^{3}$ Department of Radiology, Ultrasound Diagnostic and Physical Therapy, ${ }^{4}$ Department of Veterinary Pathology, \\ ${ }^{5}$ Department of Internal Diseases, ${ }^{6}$ Department of Animal Nutrition and Dietetics, Zagreb, Croatia
}

Received May 8, 2019

Accepted June 13, 2019

\begin{abstract}
An African pygmy hedgehog (Atalerix albiventris) (APH) was admitted to the clinic with a history of vaginal bleeding. Examination showed poor clinical status of the patient based on haemogram values. The ultrasound showed an enlarged uterus filled with an anechoic content without the presence of free abdominal fluid. Ovariohysterectomy was performed under general inhalation anaesthesia. Histopathology examination was performed on tissue samples of the uterus with the final diagnosis of an endometrial polyp with endometrial cystic hyperplasia and chronic endometritis. In regard to the diagnostic findings, therapeutic option and postoperative care performed in this case, it is important to emphasize the fact that an early diagnosis of a reproductive disease contributes to proper treatment and a positive outcome. The endometrial polyp with cystic endometrial hyperplasia and chronic endometritis should be added to the list of differential diagnoses in cases where neoplasia of the reproductive system is suspected in an APH.
\end{abstract}

Exotic pet, uterus, neoplasia, ovariohysterectomy, anaesthesia

The African pygmy hedgehog (Atalerix albiventris) (APH) has a high incidence of multiple types of neoplasia and diseases of the reproductive system, including uterine tumours (granulosa cell tumour, adenosarcoma, leiomyosarcoma, adenocarcinoma, adenoleiomyosarcoma) and mammary gland tumours (Heatley 2009; Matute et al. 2014). Predisposition to neoplasia increases with age, with geriatric hedgehogs prone the most. Since captive APHs have an average lifespan of two to five years (Matute et al. 2014), animals older than 2 years are considering geriatric. As there are no studies about the prevention and therapy of neoplasia of the reproductive system in the APH, there are no clinical indications for performing early age ovariohysterectomy.

\section{Case presentation}

A four-year-old female APH was referred to the Clinic for Obstetrics and Reproduction at the Faculty of Veterinary Medicine, University of Zagreb, Croatia (FVMUZC) due to vaginal bleeding. The clinical status of the patient was apathetic with a total lack of appetite. Clinical examination showed pale mucosal membranes, hypothermia $\left(35.9^{\circ} \mathrm{C}\right)$, tachypnoea, distended abdomen and presence of vaginal haemorrhage. Ultrasound examination was performed transabdominally using a Philips Affiniti $50 \mathrm{G}$ US machine (Philips Ultrasound Inc., Bothell, WA, USA) with linear 7.5 MHz transduce showing enlarged uterus horns with the presence of fluid in the uterine lumen and signs of endometrial hyperplasia. Free peritoneal fluid was not found. Haematology was performed by a puncture of the lateral saphenous vein. For reference ranges, we used the haemogram findings reported for the APH by Okorie-Kanu et al. (2014). Based on these findings,

Address for correspondence:

Marko Samardžija

Clinic for Obstetrics and Reproduction

Faculty of Veterinary Medicine, University of Zagreb

Heinzelova 55, 10000 Zagreb, Croatia 
the results of our patient's haemogram showed anaemia, haemoglobinaemia, decreased values of haematocrit, leukocytosis and thrombocytopaenia: RBC $1.310 / \mu 1$ (4.29-5.96), $\mathrm{Hb} 6.4 \mathrm{~g} / \mathrm{dl}(10.7-14.9)$, PCV 10\% (33.5-47), total WBC $34.710^{3} / \mu \mathrm{l}(11.5-21.65)$, differential WBC count: neutrophils 74\% (52-76), lymphocytes $21 \%$ (22-47), eosinophils $5 \%$ (0-2), PLT $173 \times 10^{9} 1$ (250-650), MCV $81 \mathrm{fl}$ (76-100), MCHC 61.6 g/dl (27.7-35.4), MCH 50 pg (22.5-31.4).

Since the only therapeutic option was ovariohysterectomy, surgery was performed immediately under general anaesthesia (inhalation mask) following premedication with $0.1 \mathrm{mg} / \mathrm{kg}$ s.c. acepromazine (Calmivet $5 \mathrm{mg} / \mathrm{ml}$, Vetoquinol, Lure, Magny-Vernois, France), $15 \mathrm{mg} / \mathrm{kg}$ i.m. ketamine (Ketamidor $100 \mathrm{mg} / \mathrm{ml}$, RichterPharma, Wels, Austria) and $0.5 \mathrm{mg} / \mathrm{kg}$ i.m. diazepam (Apaurin $5 \mathrm{mg} / \mathrm{ml}$, Krka, Novo Mesto, Slovenia). Atropine (Atropine $1 \mathrm{mg} / \mathrm{ml}$, Belupo, Koprivnica, Croatia) at a dose of $0.03 \mathrm{mg} / \mathrm{kg}$ i.m. was administered to prevent hypotension from acepromazine and to avoid hypersalivation. Pain management was performed with flunixin meglumine $1 \mathrm{mg} / \mathrm{kg}$ s.c. (Finadyne $50 \mathrm{mg} / \mathrm{ml}$, Intervet, Boxmeer, The Netherlands) in both premedication and in postoperative care, and analgesia control continued with the fentanyl (Fentanyl $0.05 \mathrm{mg} / \mathrm{ml}$, Jenssen, Beerse, Belgium) $0.1 \mathrm{mg} / \mathrm{kg}$ s.c. in anaesthesia induction and during the surgical procedure. Enrofloxacin $10 \mathrm{mg} / \mathrm{kg}$ s.c. (Enrofloxacin $50 \mathrm{mg} / \mathrm{ml}$, Baytril, Leverkusen, Germany) was continued over five days, for antimicrobial therapy. The Ringer (Ringer Lactate 280 $\mathrm{mOsm} / \mathrm{l}$, SM-Farmaceutici, Tito Scalo, Italy) was administered hypodermally at a dose of $100 \mathrm{ml} / \mathrm{kg}$. The patient was induced by $4 \%$ isoflurane (Isoflurin $1000 \mathrm{mg} / \mathrm{g}$, VetPharma, Barcelona, Spain) and maintained with 3\% isoflurane and oxygen by nasal mask. During the procedure, thermal support was provided with a heating pad. Vital signs were monitored with electrocardiogram and pulse-oximetry. Since the drug distribution rate in the APH is not described in literature, naloxone (Naloxone $0.4 \mathrm{mg} / \mathrm{ml}$, Bad, Pharmaceuticals, Cambridge CB40GW, UK) $0.16 \mathrm{mg} / \mathrm{kg}$ i.m. was given after surgery as a reversal control of the opioid (Okorie-Kanu et al. 2014). After performing the ovariohysterectomy, the enlarged uterus (Plate VIII, Fig. 1) filled with pathological fluid was sent to the Pathology Laboratory at the FVMUZC.

Tissue samples of the uterus were taken and routinely prepared for histopathological examination, stained with haematoxylin and eosin and Van Gieson. Microscopically, a pedunculated, well demarcated, unencapsulated mass was observed in the uterine lumen, arising from the endometrium compromising its lumen (Plate VIII, Fig. 2). It consisted of glandular structures of different sizes embedded within abundant fibrous connective tissue (Plate IX, Fig. 3). Some of the glandular structures were cystically dilated and contained basophilic material mixed with cellular debris. The surface of the mass was lined by single layers of cuboidal to columnar epithelium, similar to that lining the uterus. These cells were characterized by a moderate amount of pale eosinophilic cytoplasm and oval to round nucleus with finely stippled chromatin and single nucleoli. There is no evidence of atypical or mitotic activity. The surface of the mass was focally ulcerated with haemorrhages. Based on these findings a diagnosis of an endometrial polyp (EP) was established. The remaining endometrium had multifocal dilated hyperplastic glands surrounded with infiltrates of plasma cells, lymphocytes, macrophages and a few neutrophils as well as with fibrous connective tissue (Plate IX, Fig. 4). The observed microscopic lesions in the endometrium indicated endometrial cystic hyperplasia $(\mathrm{CEH})$ followed by chronic inflammation. The endometrial glands were largely cystically dilated and filled with pinkish granular material mixed with macrophages and cellular debris. Around the glands, there was abundant, mononuclear and predominantly lymphoplasmacytic cellular infiltrate. Epithelial cells of non-cystic endometrial glands had occasional cytoplasmic vacuoles. One uterine cross section contained a polypoid lesion which almost completely obstructed the uterine lumen. The polyp was largely fibrous with cystic endometrial glands, surrounded by predominantly 
lymphoplasmacytic infiltrates. Based on the histopathological findings, the assumption made earlier by ultrasound diagnosis was confirmed, and the final diagnosis was given of $\mathrm{CEH}$ with chronic inflammation and an EP.

\section{Discussion}

A wide variety of neoplasms are commonly present in captive hedgehogs, especially in the APH (Raymond and Gamer 2001; Gadrhouse and Eshar 2015; Tsai et al. 2016; Chambers et al. 2018). The average lifespan of the APH is 3-5 years and the average age for the appearance of neoplasms is 3.5 years (Heatley 2009; Matute et al. 2014). Accordingly, the hedgehog in the current case can be considered geriatric, also belonging to the group of high-risk patients for neoplasm development. Since the most common organ systems with neoplasms in hedgehogs are the reproductive, digestive, endocrine and haemolymphatic systems, the patient, having a neoplasm in the reproductive system, was classified in the group of the most common tumours (Matute et al. 2014). Given the poor clinical status of the patient, ultrasound was not performed under sedation as recommended (Heatley 2009). Had the patient been sedated during ultrasound, the EP would have likely been visualized immediately.

Based on the symptom of vaginal bleeding, the differential diagnoses could be uterine masses (adenocarcinoma, leiomyoma, myosarcoma, EP) (Philips et al. 2005; Okorie$\mathrm{Kanu}$ et al. 2014). Ovariohysterectomy is recommended as the treatment of choice for uterine neoplasia, with a good final outcome (Mikaelian et al. 2004; Heatley et al. 2005; Tsai et al. 2016). Comparing the mean haemogram reference values with the literature for the European hedgehog and the APH, it could be concluded at the time of admission that the patient was presented with anaemia, thrombocytopaenia, leukocytosis with lymphocytopaenia and had a low haematocrit (Ivey and Carpenter 2012; OkorieKanu et al. 2014). According to the observed pathophysiological and clinical status, the patient was classified as emergency ASA 5 E (ASA physical status classification system), meaning that survival cannot be expected without surgery, and any delay in treatment would significantly increase the threat to life (Anonymous 2014).

In regard to the diagnostic findings, therapeutic option and postoperative care performed in this case, it is important to emphasize that an early diagnosis of reproductive diseases in the APH contributes to better treatment with a positive outcome. The EP with CEH and chronic endometritis should also be added to the list of differential diagnoses in cases where neoplasia of the reproductive system in an APH is suspected.

\section{Conflict of interest}

This research did not receive any specific grant from funding agencies in the public, commercial, or not-for-profit sectors. None of the authors of this paper has a financial or personal relationship with other people or organizations that could inappropriately influence or bias the content of the paper.

\section{References}

Anomymous 2014: ASA Physical Status Classification System. American Society of Anesthesiologists web site. Available at https:/www.asahq.org/resources/clinical-information/asa-physical-status-classification-system. Last modified October 15, 2014. Accessed May 3, 2019

Chambers JK, Shiga T, Takimoto H, Dohata A, Miwa Y, Nakayama H, Uchida K 2018: Proliferative lesions of the endometrium of 50 four-toed hedgehogs (Atelerix albiventris). Vet Pathol 55: 562-571

Gadrhouse S, Eshar D 2015: Retrospective study of diseases of occurrence in captive African Pygmy Hedgehogs (Atelerix albiventris). Isr J Vet Med 70: 32-36

Heatley JJ 2009: Hedgehogs. In: Mitchell MA, Tully TN (Eds): Manual of Exotic Pet Practice. St. Louis (MO), Elsevier, pp. 433-455

Heatley JJ, Mauldin GE, Cho DY 2005: A review of neoplasia in the captive African hedgehog (Atelerix albiventris). Semin Avian Exotic Pet Med 14: 182-192 
Ivey E, Carpenter JW 2012: African hedgehogs. In: Quesenberry KE, Carpenter JW (Eds): Ferrets, Rabbits and Rodents: Clinical Medicine and Surgery. St. Louis (MO), Elsevier, pp. 411-427

Matute AR, Bernal AM, Lezama JR, Guadalupe MP, Antonio GA 2014: Sebaceous gland carcinoma and mammary gland carcinoma in an African hedgehog (Ateletrix albiventris). J Zoo Wildil Med 45: 682-685

Mikaelian I, Reavill DR, Practice A 2004: Spontaneous proliferative lesions and tumors of the uterus of captive African hedgehogs (Atelerix albiventris). J Zoo Wildl Med 35: 216-220

Okorie-Kanu CO, Onoja RI, Achegbulu EE, Okorie-Kanu OJ 2014: Normal haematological and serum biochemistry values of African hedgehog (Atelerix albiventris). Comp Clin Pathol 24: 127-132

Philips ID, Taylor JJ, Allen AL 2005: Endometial polyps in 2 African pygmy hedgehogs. Can Vet J 46: 524-527

Raymond JT, Gamer MM 2001: Spontaneous tumors in captive African hedgehogs (Atelerix albiventris). J Comp Pathol 124: 128-133

Tsai FY, Chang HM, Chang HK, Kao JP, Liao JW 2016: Case report: Endometrial stromal sarcoma and liposarcoma in an African hedgehog (Atelerix albiventris). Taiwan Vet J 42: 181-186 
Plate VIII

Efendic M. et al.: Endometrial polyp ... pp.337-340

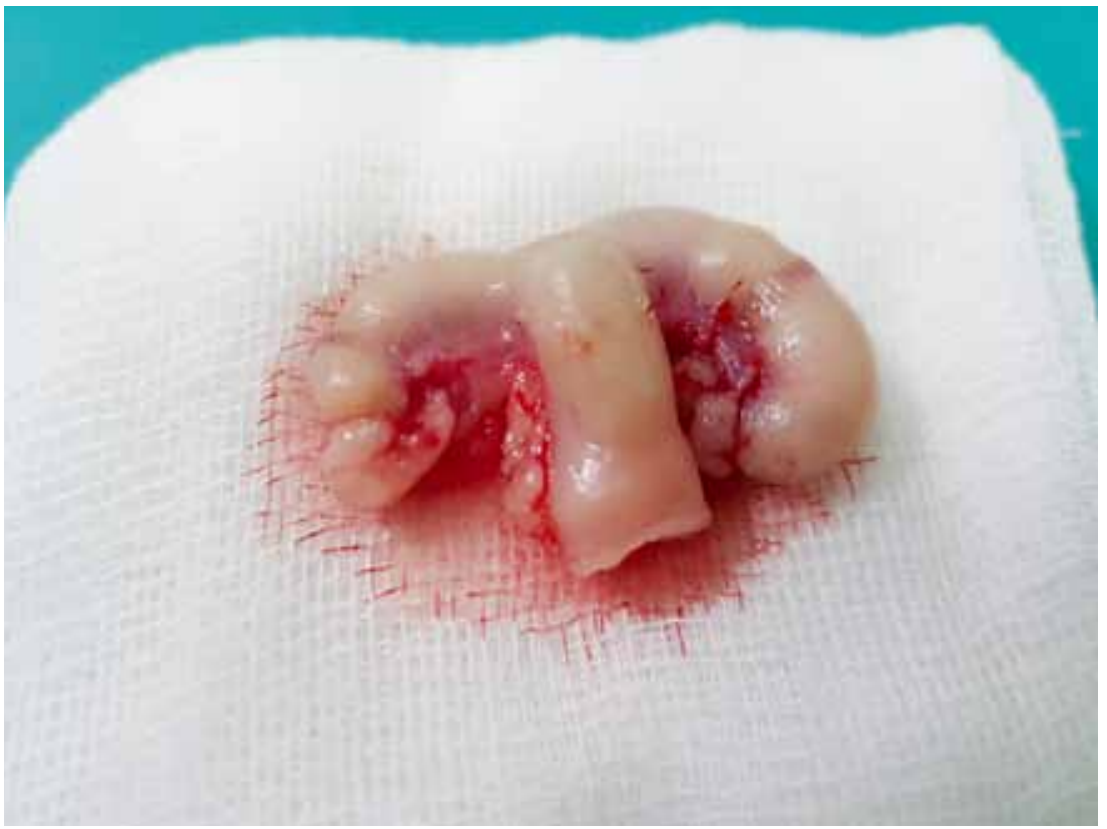

Fig. 1. Macroscopic view of the enlarged uterus of an African pygmy hedgehog (sterile compress size is $5 \times 5 \mathrm{~cm})$.

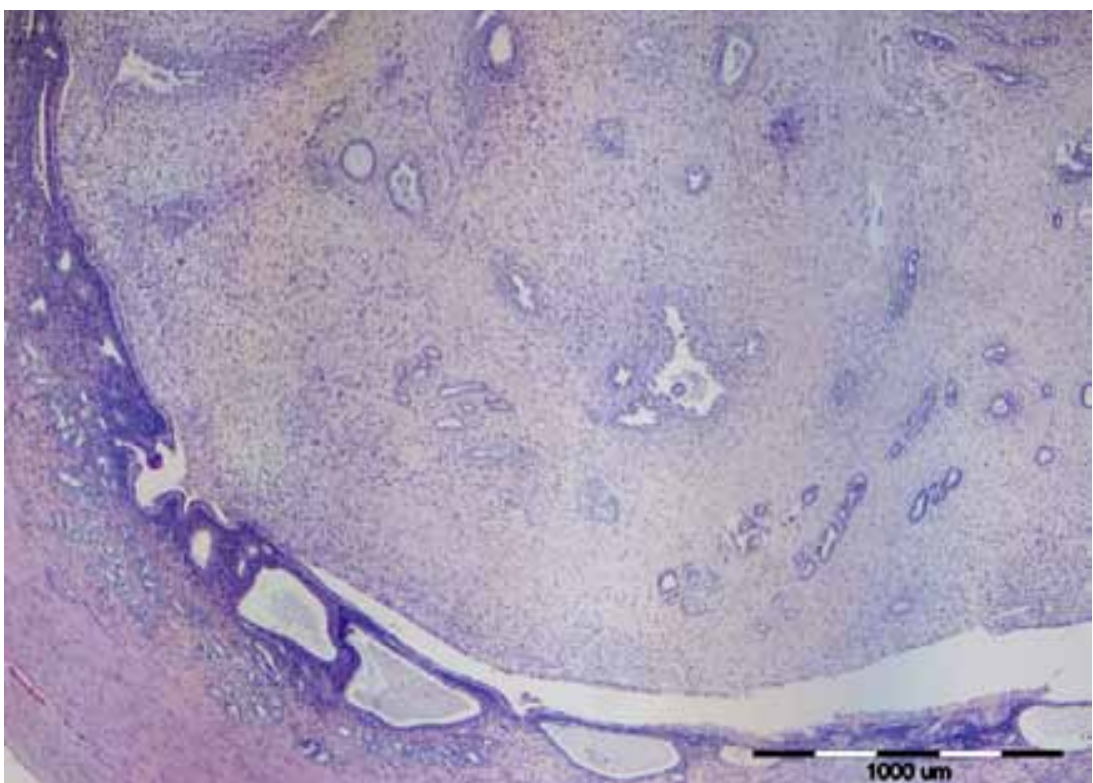

Fig. 2. Cross section of the uterus of an African pygmy hedgehog with a pendiculated mass (endometrial polyp) in the uterine lumen arising from the endometrium and compromising the uterine lumen. The mass consists of glandular structures embedded within abundant fibrous connective tissue. H\&E, magnification bar $1000 \mu \mathrm{m}$. 


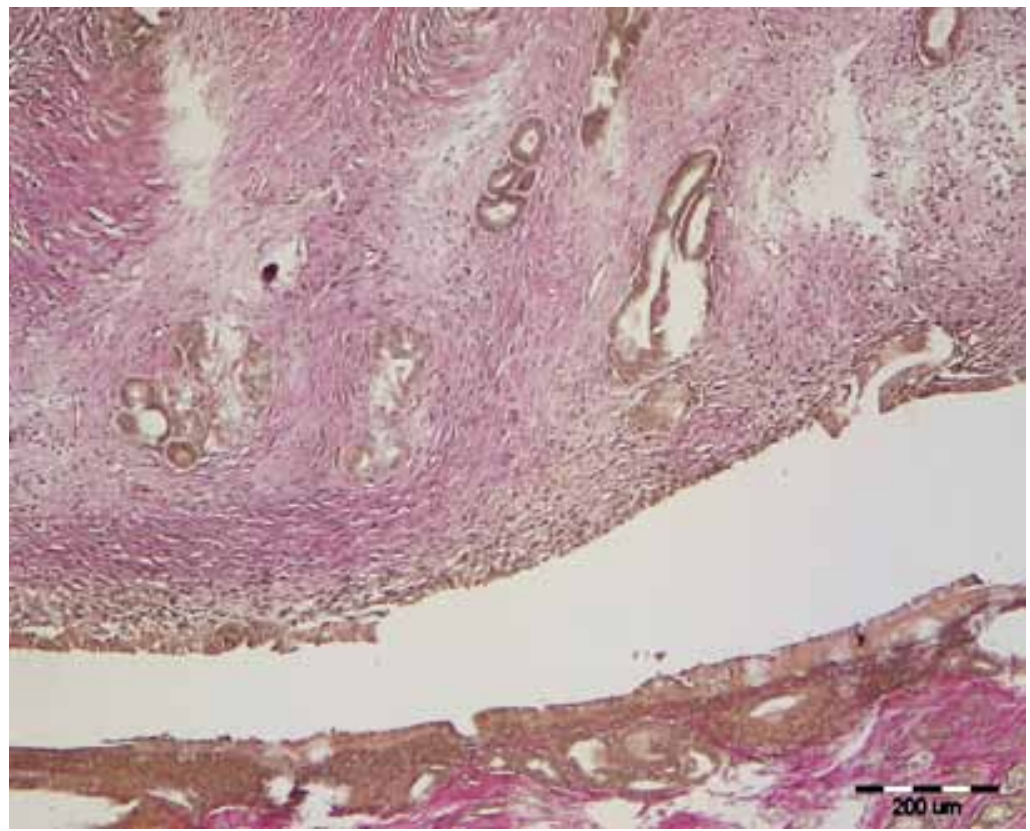

Fig. 3. The mass (endometrial polyp) in the uterine lumen. The red staining fibres are collagen. Van Gieson stain, magnification bar $200 \mu \mathrm{m}$.

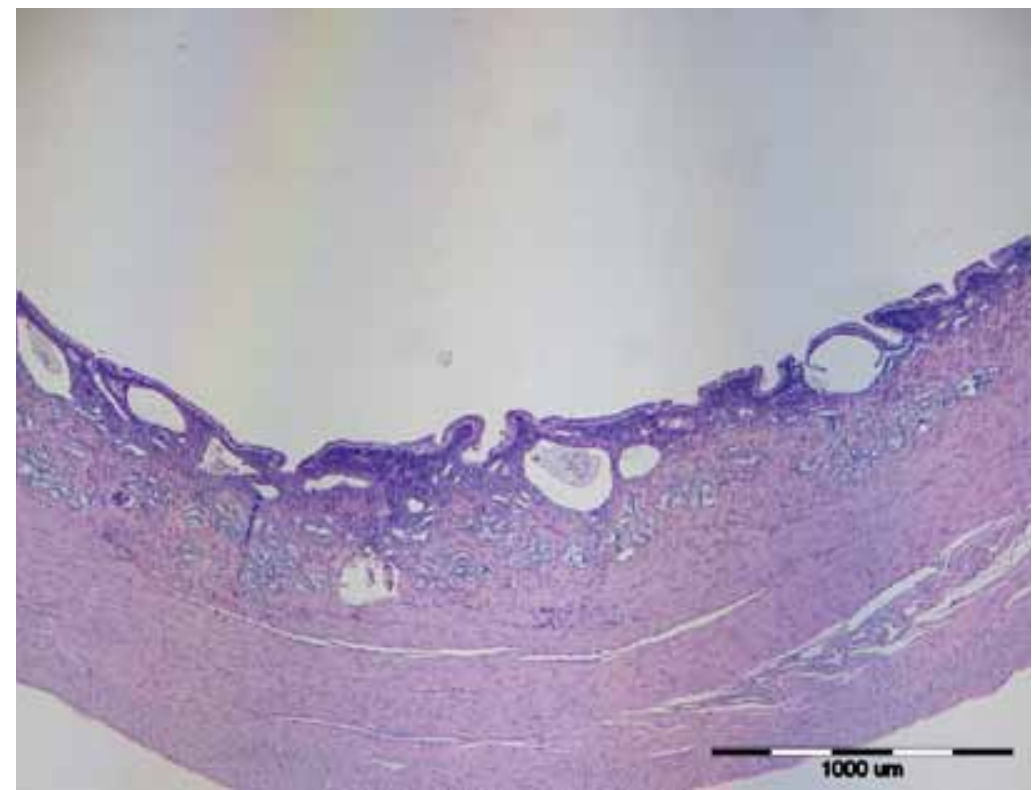

Fig. 4. Multifocal dilated glands with eosinophilic to basophilic material admixed with necrotic cellular debris in the remaining endometrium. There is inflammation, particularly around the glands. H\&E, magnification bar $1000 \mu \mathrm{m}$. 